scattering factors, but lies on planes of the type $(1 \overline{2} 0)$ and also on the basal plane (0001), the plane of the diagram. As to why there should be a concentration of electron density, which need only be of the order of $1-2$ electrons to account for the observations, we cannot yet say ; but it may perhaps be due to the overlapping of the wave-functions of the incomplete $4 d$ shell, which for ruthenium have a considerable spread. An objection to this simple

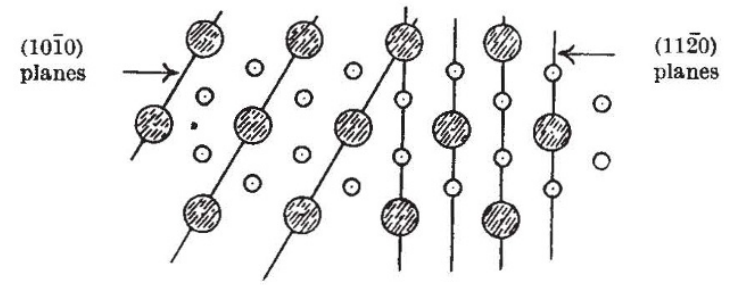

Fig. 2.

explanation is that it would require concentrations of electron density at other points in the lattice which would not agree with the present observations. Whatever may be the ultimate explanation, however, the experimental results point strongly to a concentration of electron density of the type indicated in Fig. 2.

Physics Laboratories,

G. W. Brindiey.

(Mackinnon Student of the Royal Society.)

The University, Leeds.

July 7.

${ }^{1}$ Brindley, G. W., Phil. Mag., 21, 790 (April 1936).

2 Brindley, G. W., Proc. Leeds Phil. Soc., 3, 200 (April 1936).

Brindley, G. W., Nature, 138, 290 (August 15, 1936).

- Jauncey and Bruce, Phys. Rev., 50, 408 (1936).

${ }^{5}$ Miller and Foster, Phys. Rev., 50, 417 (1936). Miller, Phys. Rev. 51, 959 (1937).

- Wollan and Harvey, Phys. Rev., 51, 1054 (1937).

\section{A New Equilibrium Diagram for the System $\mathrm{Fe}-\mathrm{C}$}

Two equilibrium diagrams, the single diagram and the double diagram, have been proposed for the system $\mathrm{Fe}-\mathrm{C}$ and we cannot, as yet, decide upon which is the correct one. The single diagram assumes that graphite never separates directly from molten iron, which was, however, recently experimentally disproved by different workers including myself. It meets with a second difficulty as it represents a metastable equilibrium; but a stable diagram for such an important alloy as $\mathrm{Fe}-\mathrm{C}$ is required.

The double diagram indicates that graphite may sometimes be formed directly from the melt; it is free from the above difficulties, but it encounters more as follows :

(1) Two diagrams (stable and metastable) are drawn with an interval less than $10^{\circ} \mathrm{C}$., and such a coupled diagram makes the matter difficult to under. stand. Several double diagrams have been proposed by different authors, and it is extremely difficult to chose from them.

(2) Two eutectic temperatures (austenite-cementite and austenite-graphite) are expected by the double diagram, but many authors have been able to find only one.
(3) The lower (metastable) lines of the double diagram express a super-cooling. We have now about 400 binary equilibrium diagrams and only three of them, $\mathrm{Cd}-\mathrm{Sb}, \mathrm{Cd}-\mathrm{As}, \mathrm{Fe}-\mathrm{C}$, include super-cooling. Super-cooling in the systems $\mathrm{Cd}-\mathrm{Sb}$ and $\mathrm{Cd}-\mathrm{As}$ is abnormal. Ordinary super-cooling is added only in the double diagram of $\mathrm{Fe}-\mathrm{C}$, which is unreasonable. We must have important reasons to justify the addition of super-cooling in the diagram, and the metastable equilibrium lines added should have been clearly proved by experiment ; but neither condition is fulfilled. The double diagram includes the supercooling at the eutectic but not that at the eutectoid (martensite formation is never included). This, again, is a self-contradictory feature of the double diagram.

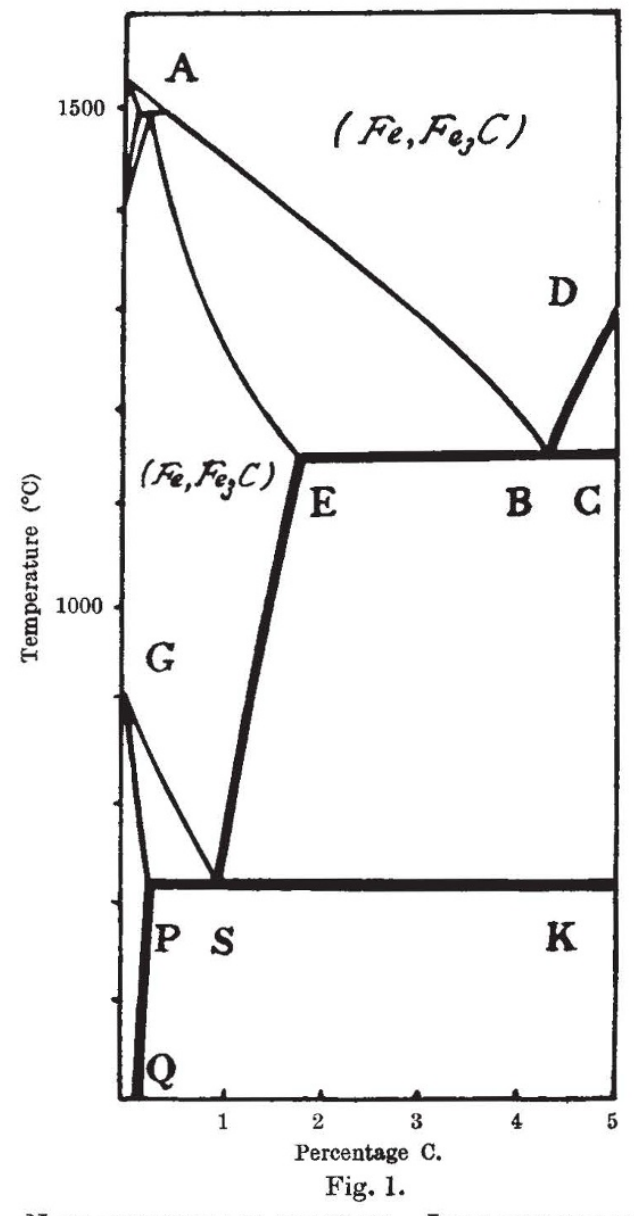

NEW EQUILIBRIUM DIAGRAM. LOW TEMPERATURES: STABLE EQUILIBRIUM FE-C; HIGH TEMPERATURES : STABLE EQULIBRIUM $\mathrm{FE}-\mathrm{FE}_{3} \mathrm{C}$.

Fig. 1 shows a new equilibrium diagram. Supercooling is omitted, thus avoiding all the difficulties of the double diagram. It shows a stable equilibrium, assuming $\mathrm{Fe}_{3} \mathrm{C}$ to decompose on solidifying or on separating from austenite, eliminating the two difficulties of the single diagram.

The details will be published in the report of this Institute.

ICHIRÔ IITAKA.

Institute of Physical and Chemical Research, Tokyo, Japan. July 9 . 